\title{
Pensamiento de Cristo e idealismo griego: para una relectura de Laberthonnière
}

\author{
Agostino MOLTENI \\ Universidad Católica de la Santísima Concepción (Chile) \\ amolteni@ucsc.cl
}

\section{Resumen}

El realismo cristiano y el idealismo griego, obra de Laberthonnière, propone una cuestión que es actual justamente por el hecho que ha sido dada por obvia, censurada y olvidada en el contexto teológico de casi toda la historia de la Iglesia. Es decir, plantea preguntas acerca de la posibilidad y conveniencia del uso de la forma mentis del pensamiento griego (expresado por su filosofía) en el ámbito de la fe cristiana y de su filosofía-teología. Para Laberthonnière, como muestra en esta obra, es imposible una concordancia entre estos dos pensamientos so pena de una desnaturalización de la misma fe cristiana. Indirectamente, esta obra pone a tema la originalidad del pensamiento de Cristo que es hebreo y no griego y cómo la asunción del pensamiento filosófico griego puede llevar a una desnaturalización del pensamiento hebreo de Cristo y de la fe cristiana vivida en la Iglesia.

Palabras claves: Idealismo griego, realismo cristiano, pensamiento hebreo de Cristo, onto-teología, sobrenatural.

\section{Thought of Christ and greek idealism: for Laberthonnière rereading}

\begin{abstract}
Christian realism and Greek idealism, Laberthonnière work, puts a question that is now precisely because it has been given by obvious, censured and forgotten in the theological context of almost the entire history of the Church. That is, it puts questions about the possibility and desirability of using the forma mentis of Greek thought (expressed by its philosophy) in the field of Christian faith and philosophy-theology. To Laberthonniere, as shown in this work, there is an impossible concordance between these two thoughts on pain of distortion of the Christian faith. Indirectly, this book puts theme originality of thought of Christ which is Hebrew and not Greek and as the assumption of Greek philosophical thought can lead to a distortion of Hebrew thought of Christ and the Christian faith lived in the Church.
\end{abstract}

Key words: Greek idealism, Christian realism, thinking of Christ, ontotheology, supernatural.

Doctor en Literatura Italiana por la Universidad de Trieste (Italia); Licenciado en Teología por el Instituto Giovanni Paolo II de la Universidad Lateranense. PDH (c) en teología, Universidad Pontificia de Salamanca. Profesor de teología y filosofía en la Universidad Católica de la Santísima Concepción. Ha publicado, entre otros, los libros: Il sorriso di Beatrice. Introduzione alla Divina Commedia (2007); Avvenimento cristiano e modernitá nel Diario di Kierkegaard (2010); Elogio de la educación. Santo Tomás de Aquino y el acontecimiento educativo (2012); El acontecimiento de la fe. El año de la fe con Benedicto XVI y Francisco (2014).

Recibido: 31/Marzo/2016 - Aceptado: 30/Mayo/2016 


\section{Introducción}

San Pablo ha afirmado: "Tenemos el pensamiento de Cristo" (1 Co $2,16)$. A este propósito, habría que preguntarse en qué medida el docetismo, en sus varias formas, no ha sido la mentalidad que más ha influido en la cristiandad (Molteni, 2015). Docetismo que, sintéticamente, consiste en la negación de la verdadera carne y cuerpo de Cristo, ya que elimina el pensamiento hebreo de Cristo. La carne-cuerpo de Cristo es así reducida a mera biología sin pensamiento. Sin embargo, junto con esta remoción del pensamiento hebreo de Cristo, en la historia de la teología y de la fe cristiana se ha caído, a menudo, en el riesgo de sustituir este pensamiento de Cristo por el pensamiento ontológico griego, platónico y aristotélico (Balthasar, 1986). Esta censura y remoción del pensamiento hebreo y no griego de Cristo lleva evidentemente a la desnaturalización de la originalidad y novedad del acontecimiento de Cristo (Oratoriana, 1972) ${ }^{1}$.

Si este es el riesgo que puede aún ser actual en la teología y en la vida cristiana, nos parece importante retomar la lección contenida en la obra del padre oratoriano Lucien Laberthonnière ${ }^{2}$ Le réalisme chrétien et l'idéalisme grec (1904) que, junto con su Essais de philosobie religieuse de 1903, fueron condenados al Index en $1906^{3}$. Esta relectura, además de ofrecer intuiciones y sugerencias, plantea preguntas que han sido olvidadas y removidas por la teología del siglo pasado y que pueden servir como aportes para la

1 Desnaturalización (dénature) es el término usado por Laberthonnière (1972) para indicar los frutos de la asimilación acrítica del pensamiento griego en ámbito cristiano (Oratoriana, 1972: 191). Tresmontant (1966: 8), en el prefacio a la edición de 1966 de Le réalisme chrétien et l'idéalisme grec que reproduce sin cambiar en nada la edición de 1904 que es la que nosotros seguimos, ha escrito que "por lo que Laberthonnière es y por su obra, puede aún ser interesante para aquellos que encuentran en él una manera conveniente de descubrir el cristianismo".

2 Laberthonnière nació en 1860 en Chapelet; amigo de Blondel (hasta el doloroso desencuentro), ordenado sacerdote en 1886 en la Congregación del Oratorio de Jesús y María Inmaculada, muere en París en 1932. Para una introducción a la vida y al pensamiento de Laberthonnière: Oratoriana (1972); Perrin (1983); Mushete (1978). Acerca de la filosofía de Laberthonnière que, como escribía en Essais de philosobie religieuse, es "un arte" (1966: 29-38), es un vivre en pensant, "vivir pensando" (1966: 35), es "buscar vivir plenamente" (1966: 31). Hendecourt (1947); Böhm (1997: 349-352).

3 Von Balthasar (1981: 105) habla a este propósito de la "tragedia humana" de Laberthonnière. Chenu ha hablado de su "sumisión dolorosa a imperativos hoy en día impensables" (Perrin, 1980: 6). Hay que recordar que Laberthonnière mantuvo una fidelidad inquebrantable a la Iglesia. Estas obras condenadas al Index fueron escritas en el periodo en que los Oratorianos, como las demás Congregaciones, fueron expulsados de Francia en 1903. Para una visión sintética del contexto teológico francés de la época de Laberthonnière, ver Vilanova (1992: 507-508). 
teología y la fe de nuestros tiempos. En efecto, es difícil negar que esta obra es fascinante, original, llena de intuiciones realmente cristianas, aunque algunas afirmaciones pueden ser equivocadamente consideradas como "modernistas".

La metodología que usaremos es la bibliográfica-documental. Lo que nos interesa, ante todo, es presentar los núcleos fundamentales de esta obra que están olvidados de modo que puedan ser conocidos. Además, estos datos se examinarán y se interpretarán de modo sintético juntamente con la tentativa de prolongar las intuiciones inconclusas presentes en esta obra ${ }^{5}$, para así llegar a sugerir algunas preguntas que puedan servir para una renovación del pensamiento teológico que se nutra realmente del pensamiento de Cristo.

La necesidad de este método es dada también por el estado del arte. En efecto, por lo que hemos podido averiguar no existen estudios detallados, menos aún recientes, sobre esta obra lo que probablemente se debe a su condena al Index $x^{6}$ Claro está, las tesis de Laberthonnière contenidas en esta obra, en su tiempo y en el nuestro, no eran ni son theologically correct, dado que se ha hablado y se habla a menudo, del encuentro fecundo entre el pensamiento cristiano con el griego ${ }^{7}$. La condena al Index ha imposibilitado una discusión sobre las tesis y preguntas de esta

4 Estamos de acuerdo acerca de la no conveniencia de incluir a Laberthonnière entre los modernistas. Ver Provencher (1992: 1014). Para el "supuesto" modernismo de Laberthonnière, ver Böhm (1994: 308-309; 1997: 349). En los archivos de la Orden del Oratorio se encuentra el testimonio de 1959 de Louis Ruy (Oratoriana, 1972: 49), en aquel entonces profesor de filosofía en Aviñón, testimonio de una conversación habida con Laberthonnière. Frente a la inminencia de la condena al Index seguida de la delación de miembros de la Action Française, cercanos a él le habían sugerido depositar un dossier con los errores doctrinales de este movimiento político del cual Laberthonnière era adversario. A lo que este responde: "Yo no soy un delator", lo que hace entender bien lo que estaba en juego y la integridad cristiana de Laberthonnière. Para él, el cristianismo de su tiempo "se encontraba más cómodo en hacer obra de policía que de hacer apostolado" (Laberthonnière, 1977: 304). Hay que recordar que, a diferencia de Laberthonnière, muchos neoescolásticos (incluyendo a Maritain) adhirieron con entusiasmo a la Action Française hasta su condena por parte de la Santa Sede en 1926 (Martina, 1978: 102-104).

5 Blondel en una carta de 1922 al cardenal Mercier había escrito: "La obra de Laberthonnière aparecerá más grande, más fuerte, más intrínsecamente filosófica y cristiana que aquella de Malebranche y de Newman" (Laberthonnière, 1966: 12)

6 Es significativo que Tresmontant (1966), en el prefacio a la edición de 1966 de Le réalisme chrétien et l'idéalisme grec, no mencione ningún estudio crítico sobre esta obra. Hay que notar que, por lo que hemos podido averiguar, no existe una traducción al español de esta obra.

Este supuesto encuentro ha sido objeto de numerosas publicaciones, lo que no entra evidentemente en nuestro propósito ni señalar ni analizar. Para una síntesis ágil, ver Jaeger (1998).

VERITAS, No 35 (Septiembre 2016) 
obra. Sin embargo, pasados aquellos años próximos a la condena, es como si la teología dominada casi totalmente por la neoescolástica hasta el concilio Vaticano II, hubiera condenado por una segunda vez al olvido eterno las inquietudes de Laberthonnière, mientras habría sido más razonable intentar entender su postura ${ }^{8}$. Tal vez examinándola con una mirada no teológicamente acostumbrada, se habría podido averiguar si había motivos que muestran su razonabilidad y su validez ${ }^{9}$. En efecto, para él, como escribía muy joven en 1882, "la idea predominante que me ha guiado en el estudio de la filosofía es la de reconocer la racionalidad del cristianismo" (Laberthonnière, 1966: 13).

Nuestra hipótesis de trabajo es presentar la cuestión fundamental que Laberthonnière pone a la fe cristiana y la teología. Queremos, por tanto, señalar las razones que Laberthonnière aporta para mostrar la incompatibilidad entre el idealismo griego y el pensamiento cristiano y al mismo tiempo indicar en qué consiste el realismo cristiano, es decir, los aportes originales que Laberthonnière ofrece a la teología y a la fe cristiana una vez que han sido librados de las categorías del idealismo griego.

Dicho de otro modo, investigando sobre esta obra, queremos mostrar la necesidad de que la teología y la fe cristiana de nuestros tiempos vuelvan a interrogarse, a inquietarse sobre la oportunidad de una asunción obvia de las categorías del pensamiento griego para comprender y testimoniar al mundo los contenidos del pensamiento de Cristo. Péguy (1992: 1269) decía que "una gran filosofía (...) es la que introduce una inquietud, que obra una sacudida, un estremecimiento". En este sentido, esta obra de Laberthonnière, que para Gilson (1962: 73) es "el mejor de sus libros", puede provocar esta inquietud, está sacudida en el pensamiento teológico contemporáneo obligándolo a re-pensar su mismo pensamiento, método y contenidos. Releyendo esta obra, queremos volver a proponer su inquietud, su sacudida: ¿Es posible pensar en griego el pensamiento hebreo de Cristo expresado en los Evangelios y en el Nuevo Testamento? Es la misma cuestión que había puesto Tertuliano (2001: 165-169) y que retomaremos en las conclusiones. Es una inquietud que el mismo Laberthonnière invocaba en contra de una "fe tranquilizadora (foi sécurisante)" (Oratoriana, 1972: 192). Como justamente ha afirmado

8 Castelli (1931) había calificado inmediatamente de modernista a Laberthonnière. Olgiati (1933: 6), aunque diga que este pensamiento "merece un estudio atento", lo califica como "despiadado adversario del tomismo". Así se puso la lápida sobre Laberthonniere en ámbito católico, es decir, neoescolástico. De aquel periódo es digno de nota el artículo del filósofo protestante Abauzit (1934), amigo de Laberthonnière.

9 Boisset escribe que Laberthonnière "no quiere ser ni un profeta ni tampoco un maestro que quiere imponer su saber a los demás", sino que "los invita a pensar, a querer, a vivir con su propia vida” (Laberthonnière, 1977: 311-312). 
Poupard a propósito de la obra de Laberthonnière y de sus amigos, "una vez que la tempestad [modernista] se ha calmado (...) ¿hemos respondido en profundidad a las verdaderas cuestiones que habían sido puestas?" (Perrin, 1975: 6).

Hay que notar de antemano que la lección de Laberthonnière no representa el menosprecio de la filosofía platónico-aristotélica. Se puede decir que su blanco no es esta filosofía, sino su uso y asimilación acrítica hecha por la filosofía y teología cristiana en la historia ${ }^{10}$ que culmina, para Laberthonnière, en el aristotelismo neoescolástico que lo ha puesto en el Index ${ }^{11}$.

De modo positivo, el aporte de esta obra de Laberthonnière consiste en la afirmación -removida en la casi totalidad de la historia de la cristiandad- de que Cristo tiene un pensamiento original que no es griego, que la fe cristiana tiene este pensamiento, que su contenido es no querer "saber sino Cristo" como dice san Pablo (1 Co 2, 1-2). Laberthonnière lo escribe claramente: "El cristianismo en lugar de superponerse a una filosofía cualquiera o ya hecha, elaborada o que se debe elaborar independientemente de él (...) no puede sino sustituirse a toda filosofía siendo él mismo la filosofía, en el sentido etimológico, es decir, la sabiduría, la ciencia de la vida por la cual se explica lo que somos" (Hendecourt, 1947: 16). Más allá del estilo dialéctico de esta afirmación, lo que importa notar es que, para él, la fe cristiana tiene un pensamiento original, que es el de Cristo que no debe ser ni mezclado ni sustituido cómodamente con un sistema de pensamiento ya hecho. En este sentido, nos parece que Laberthonnière no tiene el problema de la modernidad que tienen los neoescolásticos, no está preocupado en asimilar, validar, confirmar y corregir en sede cristiana las categorías del pensamiento moderno, ni

10 Ver en este sentido el inédito de Laberthonnière La théologie et la philosophie grec (Oratoriana, 1972: 189-192). Gilson reconoce que eran los neotomistas el blanco de los ataques de Laberthonnière, a quienes "acusaba de enseñar la noción de una naturalezaaristotélica-en-estado-de-gracia" (1962: 71), es decir, de imaginar "un círculo cuadrado". Además dice que Laberthonnière (1962: 73), "sensible en la justa medida a las diferencias que distinguen a Aristóteles del pensamiento cristiano" se indignaba "con razón de que algunos cristianos pareciesen tomar a uno por otro". A nuestro parecer, de modo injusto e superficial, dice que el "conflicto" Aristóteles-pensamiento cristiano se producía sólo "en la cabeza” de Laberthonnière (1962: 74).

11 Abauzit (1934: 7) sostiene que fueron Maurras y los neoescolásticos de la Action Française los que hicieron condenar a Laberthonnière. Para Böhm, Laberthonnière "desarrolla un enfrentamiento apasionado contra la neoescolástica" (Böhm, 1994: 307308), "una confrontación" contra ésta (Böhm, 1997: 348). Para Hendecourt (Laberthonnière, 1977: 8), "la neoescolástica de inicio del siglo XX era un aristotelismo arreglado con un barniz cristiano". Para matizar este juicio ver la síntesis sobre la neoescolástica francesa de Schmidinger (1994: 181-190).

VERITAS, No 35 (Septiembre 2016) 
tampoco de cristianizar al mundo ${ }^{12}$. A él le interesa el pensamiento de Cristo, volver a proponer su originalidad y poner en guardia a los cristianos de la tragedia que representaría la perdida de este pensamiento en favor de una acomodación a un sistema de pensamiento ya becho (platónicoaristotélico) $^{13}$.

Nos limitaremos a señalar los posibles aportes que esta obra ofrece a la apologética o, como se define en nuestros tiempos, a la teología fundamental. No es nuestra intención comparar esta obra de Laberthonnière con la apologética de su tiempo, referirnos a las fuentes que pueden haber influenciado sus tesis o detenernos en los aspectos de teología dogmática que esta obra contiene.

Siguiendo la lección de Laberthonnière, ante todo señalaremos como la utilización sumisa del pensamiento idealista griego por parte del pensamiento cristiano lleva como consecuencia a la visión de un sobrenatural deshumano. En seguida, veremos la diferencia entre el Dios hebreocristiano y el de onto-teología griega. Proseguiremos señalando en qué sentido el idealismo griego impide la concepción de una sociedad Dioshombre lo que, al contrario, es posible en la visión hebreo-cristiana. Luego verificaremos como la asunción del idealismo griego impide entender de modo adecuado la contemporaneidad de Cristo y los métodos históricos críticos. Ulteriormente indicaremos lo que Laberthonnière afirma sobre el pensamiento de Cristo. En las conclusiones trataremos de mostrar como su lección pone preguntas y cuestiones que pueden ser útiles para repensar la teología y la fe cristiana actual.

\section{Un sobrenatural deshumano}

$\mathrm{El}$ problema fundamental que interesa a Laberthonnière en "El realismo cristiano y el idealismo griego" es la sobrenaturalidad del acontecimiento cristiano que puede ser equivocadamente pensada como "algo que habría sobrevenido a la humanidad por un decreto arbitrario de una voluntad dominadora" (Laberthonnière, 1904: 7); lo que obliga a pensar en un sobrenatural puramente exterior, de pacotilla (pacotille) (Laberthonnière, 1904: 8). De modo no pertinente, Hendecourt (1947: 119) escribe

12 En contra de la pretensión de los neoescolásticos de cristianizar el mundo, Laberthonnière escribía que lamentablemente "se asimila la conquista cristiana con una conquista del mundo. (...) Sin embargo, la religión que se quiere imponer por la fuerza cesa de ser religión" (Abauzit, 1934: 32).

13 No podemos detenernos sobre la influencia de Blondel presente en Laberthonnière, ni sobre las otras fuentes (san Agustín, Pascal, Bérulle, Descartes, Boutroux entre otros) de su pensamiento apologético. Para estas fuentes, remitimos a Hendecourt (1947: 10-16). 
que la apologética de Laberthonnière se debe entender como "el llamado a las conciencias a descender al fondo de ellas mismas para ponerlas en presencia del infinito que llevan en sî’. Esto significa asimilar la apologética de Labethonnière al gnosticismo modernista, lo que es falso. La apologética de éste consiste en mostrar la conveniencia humana, es decir, razonable, de la relación con Cristo. Para él, Cristo es el camino en cuanto mediador entre Dios y los hombres (Laberthonnière, 1904: 69).

Para Laberthonnière (1904: 5-36) esta concepción extrinsecista de lo sobrenatural es deudora de la influencia del idealismo griego que ha engendrado en el seno de la cristiandad una falsa idea de surnaturel. En efecto, la filosofía griega se pregunta sólo acerca de las cosas, no por la vida del hombre y por su sentido (Laberthonnière, 1904: 13). Se interesa sólo de cosas, de sus esencias y no de actos. Hendecourt (1947: 6) ha señalado justamente que "la palabra física despertaba en él desconfianza, evocaba el adversario", adversario que para esta autora es sólo Aristóteles, mientras debería ser incluido también el nombre de Platón.

Para Laberthonnière, y esta es una primera gran lección, el pensamiento filosófico y teológico se ha fijado sólo en cosas, en esencias, es un pensamiento naturalista que se ha desinteresado de los actos imputables por sus frutos-beneficios. La concepción de Laberthonnière rechaza así cualquier naturalismo de causas-efectos, rechaza cualquier reducción del ámbito del pensamiento a la mera naturaleza, pues no le interesa la naturaleza de las cosas, le interesan actos.

Es más, el idealismo griego, a través de la abstracción ${ }^{14}$, llega al conocimiento de ideas que son formuladas en conceptos, de modo que, en lo que es móvil, se fija sólo en la estabilidad y la inmovilidad de las ideas universales que son las únicas que tienen derecho de ciudadanía. Entre estas ideas, la idea de Dios es "una especie de idea de ideas" (Laberthonnière, 1904: 15-16) ${ }^{15}$. Al contrario, para Laberthonnière (1966: 84), "se adquiere el conocimiento de Dios como se adquiere el conocimiento de un amigo, viviendo de su vida, penetrando en su intimidad, deviniendo él mismo".

14 Para Laberthonnière, "el racionalismo griego pretende explicar lo concreto de la experiencia por medio de la abstracción que se saca de esta experiencia” (Hendecourt: 1947: 8)

15 Acerca de la afirmación de Dios en Laberthonnière (1966: 80-85), ver los Essais de philosobie religieuse. Para él la pruebas de la existencia de Dios "no tienen una eficacia ineluctable para hacer creer en Dios" (Laberthonière, 1966: 83). Esto seguramente no debe haberle gustado a los neoescolásticos de su tiempo que se afanaban en amontonar este tipo de pruebas. Acerca de la concepción de Dios en Laberthonnière, aunque con muchas reservas, ver Guerin (1939: 5-32).

VERITAS, No 35 (Septiembre 2016) 
Como consecuencia del idealismo griego, la salvación para el hombre consiste en "pensar en ideas" (Laberthonnière, 1904: 17), es decir, consiste en una contemplación de un "ideal estático" (Laberthonnière, 1904: 20) al cual el hombre en última instancia es sumiso ${ }^{16}$. Esto porque la experiencia real, individual, es el "escándalo del pensamiento griego" (Laberthonnière, 1904: 18). Para este pensamiento se puede conocer sólo el universal, lo abstracto que, desde arriba, domina la experiencia real. Aunque Laberthonnière no lo diga, hace intuir que la epistemología griega es como un superyó que desde arriba (epi) domina la competencia individual del sujeto que vive la experiencia real. En efecto, el idealismo griego considera intolerable que se "piense personalmente" y quiere la "abdicación de la autonomía del sujeto y la renuncia a su humanidad" (Laberthonnière, 1904: 106).

Este pensamiento idealista griego pregona sólo la fuga del mundo hacia otro mundo, dejando que la experiencia real vivida por los hombres sea dominada por el Destino (Laberthonnière, 1904: 19), por la heimarmene despótica e impersonal griega. La vida del hombre, vivida frente a este Dios que es un mero ideal estático que debe ser contemplado catatónicamente, no es urgida a ninguna respuesta. Abauzit observa (1934: 24) que para Laberthonnière "la afirmación de Dios no es el resultado de una visión sobre-sensible (...) ni es la conclusión de un razonamiento”. Para el idealismo griego, se trata sólo de ver, no de obrar, ya que este ideal estático "es y nada más" (il est, et rien de plus) (Laberthonnière, 1904: 19), es decir, no pide ningún trabajo, ningún acto por parte del hombre, ya que este ideal, este Dios es mero ser que ya es y que no necesita trabajar, acontecer.

Se podría decir, prolongando su lección, que Laberthonnière individúa aquí el enorme error del idealismo griego que ha pensado sólo en el ser y en el devenir, desconociendo absolutamente una tercera realidad, la del ser que propiamente es "acontecer". El ser es el trabajo de acontecer. Además indica que este pensamiento griego lleva a la negación de la dimensión histórica de la fe cristiana. De hecho, esta concepción del ser que ya es y nada más, afecta la misma concepción de Dios que es pensado por el idealismo griego como exterior al hombre ${ }^{17}$, fuera de la historia. El hombre, como consecuencia, no puede vivir de este Dios, pues es "un universal que es y que no acontece" (Laberthonnière, 1904: 23).

16 A este respecto, no estamos mínimamente seguros que la lección de la Dei Verbum, es decir, que la revelación es una Persona, Cristo y no un conjunto de ideas o valores, ha sido asimilada en el ámbito de la teología y de la fe cristiana de nuestros tiempos posconciliares.

17 Idealismo ontológico griego de que está lleno el pensamiento neoescolástico para el cual "Dios es el fin extrínseco del hombre" (Guerin, 1939: 9). 
El esencialismo griego introducido en el pensamiento cristiano puede muy bien pensar en los atributos ontológicos de Dios (Infinito, Todopoderoso, Bien, Acto puro que piensa en sí mismo). Sin embargo, estos atributos ontológicos para Laberthonnière no son mínimamente interesantes, pues son inimputables como actos en la historia. El Dios del idealismo griego es sólo un Dios soberano de un mundo de ideas, un Dios que está ya hecho, que no debe hacer nada más que "permanecer siempre lo que es independientemente de lo que pase en la realidad" (Laberthonnière, 1904: 24). Dios es, así, "totalmente otro", totalmente extraño y exterior al hombre, pues entre el hombre y Dios hay "una indiferencia completa" (Guerin, 1939: 8).

Para Laberthonnière la causa de esta concepción es la tendencia del pensamiento griego a "fijar lo que por su naturaleza es movimiento" (1904: 24). El hombre viviente, que es movimiento y acción ${ }^{18}$, es visto sólo en una "fijeza y determinación lógica" (Laberthonnière 1904: 25 26), desinteresándose de la existencia histórica, del porqué los hombres nacen y mueren. Aislado en su contemplación de la idea de Dios, "cada sabio se basta a sí mismo, ignorando cualquier solidaridad con los otros hombres y con los acontecimientos de la historia" (Laberthonnière, 1904: 27-28), contentándose con un dogmatismo abstracto e individualista, pues se trata sólo de "pensar estáticamente" (Laberthonnière, 1904: 28).

Notamos que Laberthonnière está lejos de condenar el pensamiento filosófico-metafísico griego del pueblo, el de los trágicos, de los historiadores, de los estoicos y epicúreos ${ }^{19}$. Su blanco es el platonismo y el aristotelismo, el idealismo de estas filosofías que superpone su ideal abstracto a la realidad, lo que ha tenido como efecto histórico la incapacidad de crear una "organización social" (Laberthonnière, 1904: 29), pues este idealismo era una mera superposición (superposition) a las tradiciones religiosas y morales del pueblo griego que no tenían nada en común con él.

18 Pensamos que en el pensamiento de Laberthonnière ha influido el de Bergson, como es confirmado por este en una carta de 1901 dirigida al que llama el "filósofo" Laberthonnière. En esta carta lo agradece por haber manifestado "simpatía" hacia sus ideas que quieren ser "un esfuerzo para entrar en contacto inmediato e íntimo con la realidad vivente” (Perrin, 1975: 29).

19 Para Laberthonnière cada hombre hace metafísica: "por el mismo hecho de vivir, tout le monde en fait, todos la hacen" (Laberthonnière, 1966: 33). Hay que notar que para él, los primeros cristianos valoraron el lenguaje griego para expresar los contenidos de la fe (Laberthonnière, 1972: 189). En estos primeros siglos de la fe cristiana para Laberthonnière se supo distinguir la tarea que los cristianos tenían de "expresar" (exprimer) los contenidos de la fe, no de "pensar" (penser) en griego (Laberthonnière, 1972: 189-192). Para él, la desnaturalización producida por el pensamiento griego asumido por los cristianos para pensar la fe, se actúa en la Edad Media.

VERITAS, No 35 (Septiembre 2016) 
El resultado es que los sabios filósofos han constituido una "ciudad" infinitamente distinta de la de los artesanos, soldados y esclavos (Laberthonnière, 1904: 30).

El idealismo griego ha sabido sólo "pensar el mundo [las "cosas"] para olvidarse de vivir, encantarse de especulaciones para sustraerse al misterio desgarrador de la existencia y a la responsabilidad que la existencia implica. (...) Ha hecho del tiempo un sueño de la eternidad" (Laberthonnière, 1904: 31). Esta pretensión, sin embargo, no eliminaba la tristeza de la existencia, la fatalidad. Y, si bien los poetas, los estoicos, los epicúreos, los historiadores, los moralistas no se contentaban con este Dios ideal, el platonismo y el aristotelismo dominaron en la historia del pensamiento, olvidando el esfuerzo existencial del que había nacido la misma filosofía (Laberthonnière, 1904: 33-34).

Nos hemos detenido sobre este aspecto del pensamiento de Laberthonnière, pues no sólo es contracorriente aún en nuestros días, sino porque pensamos que es exacto. Desarrollando sus afirmaciones, se podría decir que, de este modo, la nada que es el mundo de las ideas es creído real y la realidad viviente, movediza, flexible, es considerada irrealidad. ¿El origen del nihilismo no está ya en la ontología griega en su abstracta y estática presencia del ser sin ninguna conveniencia con el hombre, de modo que el ser es "nada" para la existencia humana?

\section{E1 Dios cristiano y la onto-teología griega}

Si el idealismo griego es meramente un "sistema de ideas fijo e inmóvil" (Laberthonnière, 1904: 38) que acecha desde arriba con su episteme dominadora la realidad en movimiento, para Laberthonnière no puede haber sino contradicción con el cristianismo, o mejor, con Cristo, que "no es un concepto, una idea general, ya que nosotros entramos en relación con él no por una relación lógica” (Laberthonnière, 1904: 39). Es más, Cristo es un acontecimiento en la historia que supera el historicismo positivista. El cristianismo es una historia de actos y en acto, más que una simple enumeración de hechos neutrales que podrían ser fichados por el historicismo positivista. La Escritura, en efecto, es "interpretación de actos" que "deben ser vistos desde adentro, desde el acto vital de donde emanan", pues la historia sagrada es historia de "la acción misma de Dios" (Laberthonnière, 1904: 46-49). A este propósito, Boisset ha mostrado cómo la lección de Laberthonnière consiste en incluir en la fe la dimensión histórica que era desconocida por una teología tributaria del idealismo griego (Laberthonnière 1977: 305-308). Esta inserción de la fe en la historia que Laberthonnière desea expresar en su obra, para Boisset, se actúa por su arraigo en "una visión bíblica de un Dios perso- 
nal" (Laberthonnière, 1977: 305), es decir, de un Dios que demuestra su existencia en cuanto actúa.

Esta acción de Dios en la historia es testimoniada en el Génesis donde es evidente que hay "un acto de Dios, un acto positivo por el cual las existencias no derivan de una esencia; ellas no son deducidas, ellas son hechas; $y$, por eso, la existencia no se explica lógica y estáticamente, sino histórica y dinámicamente" (Laberthonnière, 1904: 53). De este modo, el peligro mortal para la fe cristiana consiste justamente en el hecho de servirse del idealismo griego para definir la naturaleza del acontecimiento cristiano, llegando a hacer coincidir el contenido del anuncio cristiano con doctrinas inmutables, abstractas, estáticas. La imposible relación del idealismo griego con el realismo cristiano estriba justamente en que el ser griego que es estático, ya hecho, concluido, antecedente, patológicamente presupuesto, no puede jamás ser Sujeto que encuentra al hombre en su deseo de salvación. Como afirma justamente Abauzit (1934: 16), para Laberthonnière "el ser es siempre un sujeto". Es como si Laberthonnière dijera, usando una expresión moderna, que de la ontoteología de un Ente supremo jamás puede engendrarse el acto de un Sujeto. Algo jamás puede ser Alguien y el ser entendido como cosa, como causalidad natural, jamás puede hacer a Alguien capaz de un acto jurídica y económicamente imputable por el hombre, jamás puede ser satisfacción, camino, verdad y vida para el hombre ${ }^{20}$.

Hendecourt (1947: 5) ha escrito que "el centro del pensamiento de Laberthonnière es el problema del destino". Destino que, a nuestro parecer, debe ser entendido en Laberthonnière como heimarmene, una necesidad y fatalidad a la cual el hombre y Dios mismo (incluyendo a Cristo) serían sometidos, sin ninguna posibilidad de relación de partnership humana y divinamente razonable. En efecto, es el dios de Aristóteles que no tiene ningún provecho en la relación con los hombres, ya que lo único que le interesa es un "provecho de dominación” (Guerin, 1939: 8).

A este propósito, la apologética de Laberthonnière quiere liberar a Dios y al hombre de su cosificación naturalista, de un Destino-beimarmene mecánicamente prestablecido (ya sea en Dios, ya sea en el hombre), pues la urgencia de Laberthonnière es "una respuesta al problema de la libertad” (Hendecourt, 1947: 9) ${ }^{21}$. La apologética de Laberthonnière es la de

20 No concordamos con lo que escribe Böhm (1997: 350) para el cual Dios, según Laberthonnière es "causa eficiente real y efectiva". Esto significa concebir al Dios de Laberthonnière como "naturalista", de la causalidad natural.

21 A este propósito, ver lo que escribe Laberthonnière sobre "el deber de la apologética en la hora presente" (Oratoriana, 1972: 173-178). En aquellos tiempos, la apologética de Laberthonnière era acusada de "querer hacer predominar lo subjetivo sobre lo objetivo" (Poulat, 1974: 391).

VERITAS, $N^{0} 35$ (Septiembre 2016) 
la cooperación Dios-hombre y de la cooperación del hombre con los demás: "Todo se hace por la cooperación (cooperátion)" (1966: 102; 106) 22. Es una cooperación universal, ya que no se puede decir que para Dios sea suficiente el hombre excluyendo a los demás hombres: "Necesitamos de todos para afirmarnos a nosotros mismos y para afirmar a Dios" (Laberthonnière, 1966: 96).

Si se trata más bien de la cooperación Dios-hombre, es evidente para Laberthonnière que el Dios bíblico-cristiano no está ya hecho, inmóvil y que, por tanto, naturalmente no deba trabajar (Aristóteles). El Dios cristiano es capacidad y poder de acción, acto en movimiento, acto y movimiento de su pensamiento, pues el acto remite al pensamiento, lo que se muestra en la creación y en la redención. Para Laberthonnière, el dogmatismo moral que pregona es fruto de "la participación, intervención, colaboración, cooperación (concours) de Dios, de los otros y de nuestra misma acción" (Laberthonnière, 1966: 103). Es un dogmatismo que afirma el ser en el acto imputable. En este sentido escribe que "yo no puedo afirmarme a mí mismo, sin afirmar a Dios y sin afirmar a los otros" (Laberthonnière, 1966: 102). De este modo, el Dios cristiano es un Dios que se hace presente en la historia, que no huye del tiempo y del espacio en una dimensión meramente "sobrenatural" como el dios de la filosofía griega. Es un Dios que puede ser "constatado", es decir, juzgado, imputado, como viviente en la historia. Dios existe porque actúa. No existe Dios sino en su imputabilidad.

De aquí se origina el realismo cristiano que sería radicalmente distinto del idealismo griego, entendido como una fuga hacia un hiperuranio habitado por Ideas (Platón) o por un Motor inmóvil (Aristóteles). El Dios cristiano es un Dios presente en la historia, no es el Dios abstracto y estático griego, un Dios-idea universal e inmóvil con su dogmatismo abstracto, sobre-natural, separado radicalmente del hombre. El dogmatismo moral de Laberthonnière es el que quiere imputar a Dios por sus actos-comportamientos, no por su esencia, lo que sería un dogmatismo ilusorio $^{23}$. Es más, el Dios-persona cristiano demuestra en qué sentido es propiamente sobre-natural en cuanto no es un Dios-naturaleza, sino justamente un Dios-persona que acontece en la historia de los hombres y que, por eso, supera la causalidad natural inimputable. A este propósito, hay que notar que Laberthonnière condena cualquier divinización del mundo característica de los griegos.

22 Ver el artículo de Hendecourt "Le Christ et l'homme dans le mouvement de l'histoire" (Oratoriana, 1972: 163-170) y Abauzit (1934: 29).

23 A este propósito ver Abauzit (1934: 16-19). El mismo autor afirma que este dogmatismo pretende alcanzar la certeza “por la acción” (Abauzit, 1934: 30). 
Podríamos así decir que la gran intuición de Laberthonnière es afirmar que el Dios cristiano es un Dios jurídico, es decir, que actúa en la historia y, por eso, se hace imputable. Es un Dios que, en Cristo, por ser humano no pierde nada de su sobrenaturalidad: el carácter humano del cristianismo no perjudica su carácter sobrenatural (Laberthonnière, 1904: 103-116). Es más, el hecho que "la revelación divina no consiste en introducir en el espíritu humano una verdad que es exterior y extraña a la realidad viviente que nosotros somos" (Laberthonnière, 1904: 105) manifiesta aún más su sobrenaturalidad. Esto significa que el ser de Dios no es no es cosa, sino sujeto jurídico sobre-natural. Un Dios superpuesto a la historia de los hombres sería inimputable, sería sólo Algo, un Destino que se debe aceptar servilmente con sumisión, Algo que no respondería para nada por sus actos frente a los hombres (Laberthonnière, 1904: 105). Al contrario, la revelación de Cristo consiste justamente en esta imputabilidad de Dios en la historia: en Cristo, Dios se hace imputable, ya que actúa en el presente de la historia y no permanece superpuesto al hombre. Y el hombre no es un ser sumiso a Dios, sino un cooperador en la oeconomia salutis, como afirma san Pablo: "Nosotros somos cooperadores de Dios" (1 Co 3, 9).

En efecto, para Laberthonnière, el servilismo es la otra cara del autoritarismo (Oratoriana, 1972: 222). A este propósito, es muy interesante la observación que hace cuando afirma que no sólo la asunción del idealismo de Aristóteles ha llevado a la desnaturalización de la fe cristiana, sino también la asimilación "del espíritu mahometano que los filósofos árabes habían inculcado a la escolástica" (Oratoriana 1972: 221). Esta observación es interesante porque profetiza una islamización de la fe cristiana, es decir, la sumisión supina a un Dios ontológicamente grande, afirmación que merecería un desarrollo mucho más amplio, lo que no podemos hacer en el espacio de este artículo.

\section{La ciudad cristiana de Dios y del hombre}

De modo agudo, Laberthonnière afirma que la oposición entre el cristianismo y la filosofía ontológica griega es la oposición entre "dos ciudades" (Laberthonnière, 1904: 99). La ontología griega habla de un "Dios-idea suprema", de un "Dios-naturaleza" (Dieu-nature) (Laberthonnière, 1904: 65) ${ }^{24}$, de un "Dios como el de Aristóteles que es cosa absolutamente hecha, terminada, completa, determinada y que, como conse-

24 Laberthonnière, que había seguido los cursos de Boutroux, fue influenciado por este. Boutroux distinguía claramente el orden de la naturaleza, físico, con sus leyes predeterminadas, del orden meta-físico donde él encontraba Dios y el hombre.

VERITAS, No 35 (Septiembre 2016) 
cuencia, no actúa, pues no tiene nada que hacer" (Laberthonnière, 1904: 67). Un Dios, por tanto, sobrenatural, ab-solutus, desligado de cualquier trabajo de partnership-sociedad con los hombres, en cuanto separado de ellos y de su pensamiento jurídico-económico que imputa a Dios por sus frutos-beneficios. El cristianismo, al contrario, habla de un Dios-persona (Dieu-personne) (Laberthonnière, 1904: 66), es decir, de un Dios que vive y actúa, que es poder actuante, distinto del acto puro estático de Aristóteles. Como afirma Abauzit (1934: 31), para Laberthonnière "el Dios de Platón y Aristóteles es la Idea suprema, inmóvil, en su perfección, inoperante y estático. (...) El Dios bíblico es Dios-persona, un poder de actuar El Dios cristiano es Trinidad, "una sociedad que se engendra ella misma desde adentro (...) acción eterna de una eterna vida y no una idea o una esencia fijada en un eterno reposo" (Laberthonnière, 1904: 69).

De este modo, el hombre no es $\operatorname{cosa}^{25}$, sino persona, a imagen y semejanza del Dios-persona. Para Laberthonnière (1904: 23), el hombre "no es un ser que está cerrado en lo que es". Es evidente la diferencia entre la antropología ontológica estática del idealismo griego y la antropología cristiana del acontecimiento-hombre. Se podría decir, continuando el pensamiento de Laberthonnière, que el hombre es engendrado no creado, es decir, que el hombre no es una cosa creada con sus leyes físicas predeterminadas de causa-efecto que pueden ser silogísticamente deducidas, sino que, por ser engendrado, es meta-físico, sobre-natural. De aquí que el hombre, por ser meta-físico y sobre-natural (es decir, que no tiene una naturaleza ontológicamente predeterminada por leyes mecánico-físicas), es el único socio-partner adecuado de una Alianza ${ }^{26}$. Böhm escribe (1997: 350) que Laberthonnière está lejos de querer "reducir lo sobrenatural a lo natural, sino que cree que lo natural está siempre penetrado por la gracia divina". Se podría especificar mejor diciendo que, para Laberthonnière, lo sobrenatural no se relaciona con el hombre como con algo natural, sino que con alguien que es imagen y semejanza de lo sobrenatural.

25 Ver lo que dice, sin llegar a nuestras conclusiones Guerin (1939: 11-12).

26 Sobre la "ontología de la persona" de Laberthonnière, ver el artículo de Douchevsky (Oratoriana, 1972: 131-161). Tresmontant (1966: 9-10) ha observado que Laberthonnière "ha explorado muy profundamente ciertos aspectos de la ontología cristiana". Es más, se puede decir que ha mostrado la diferencia entre la ontología griega y la cristiana. Para Tresmontant (1966: 10), el "error histórico" de Laberthonnière ha sido no reconocer la novedad de la ontología cristiana de Tomás de Aquino. Hay que notar que Laberthonnière ha conocido a Tomás sólo a través de los neoescolásticos seguidores de la Action Française de Maurras, que criticaba ferozmente (Martina, 1978: 103). Para él, si bien Tomás de Aquino "ha evitado hacer de la fe una vida, esto lo evitaba teóricamente, no prácticamente, ya que deja entrever que su alma es capaz de vibrar, de saborear intenciones infinitas, etc.” (Oratoriana, 1972: 191). 
A este propósito, se podría decir que, para Laberthonnière, la prueba de la existencia de Dios-persona (no de un Dios-cosa, ni Causa mecánica) es justamente la existencia de los hombres meta-físicos, engendrados no creados-causados ${ }^{27}$.

En esta antropología meta-física cívica de Laberthonnière, la revelación de Cristo no es meramente una "manifestación exterior y material" (1904: 17) que acontece en un ámbito extraño a Cristo. En efecto, el Verbo in propria venit, "vino entre los suyos" (Jn 1,11). Decir esto significa afirmar que lo sobrenatural cristiano no es extrínseco al hombre metafísico, que la revelación no es mera exterioridad, cosa que está ahí ya hecha. Sin embargo, hay que notar que jamás Laberthonnière ha reducido el carácter exterior de la revelación ni ha reducido ésta a una toma de conciencia gnóstica y modernista de la religiosidad ya presente en el hombre.

Siendo que los hombres no son esencias que derivan y emanan lógicamente de la esencia de Dios, la relación hombre-Dios es moral, es comportamiento (sentido etimológico de mos-moris), no es "mera sumisión de la inteligencia sino conversión integral del ser" (Laberthonnière, 1904: 22). Es amor, es la "metafísica de la caridad" que es el tema que Laberthonnière desarrolló en las Conférence de Notre Dame entre los años 1925-1927 (Laberthonnière, 1966: 10; Hendecourt, 1947: 9). Para él, la metafísica es una relación que no se da entre objetos-naturalezas físicascosas, sino entre sujetos ${ }^{28}$, pues "el ser no es una cosa, un objeto. Los otros son sujetos, como yo soy sujeto" (Abauzit, 1934: 25-26).

En este sentido, los hombres no pueden relacionarse con Dios con una lógica aristotélico-deductiva (la de una causa-efecto naturalistafísica), sino viviendo esta relación que es siempre acontecimiento, amor (Laberthonnière, 1904: 71). Abauzit (1934: 30) afirma de modo muy pertinente que para Laberthonnière "Dios no viene una vez por todas, en un momento dado, por una idea que entra en el espíritu. Él viene sin cesar", es decir, es acontecimiento. Dios es "Quien es", "acción suprema” (Laberthonnière, 1904: 73), según la lectura que él hace de Ex 3, 14, es decir, de la revelación del nombre de Dios a Moisés. No es un Dios "inerte más arriba del movimiento y de la vida" (Laberthonnière, 1904: 73).

A este propósito, se podría así decir que Laberthonnière contesta a la idea de la analogia entis de la escolástica decadente, la cual "partiendo de

27 En sentido parecido, pero distinto de nosotros, Guerin (1939: 31) escribe que "la existencia de los otros es la mejor prueba de la existencia de Dios-caridad".

28 Para la idea de metafísica de Laberthonnière como necesidad de cada hombre (Laberthonnière, 1966: 33-38).

VERITAS, No 35 (Septiembre 2016) 
las cosas, de los efectos, pretende llegar a la Causa suprema que es Dios por un razonamiento silogístico" (Guerin, 1939: 28). De las cosas no se llega a Alguien, se llega a lo máximo a Algo, a una Causa predeterminada, a un "Destino" que decide mecánicamente lo que debe ser causado. Para Laberthonnière, el hombre (y no las cosas, los entes naturales) es la analogía conveniente para conocer a Dios como Alguien, Persona, ya que el hombre es imagen y semejanza de Dios, es decir, alguien, no algo. Para él, "el hombre es el camino de la Iglesia", como dirá la encíclica Redemptor hominis (Juan Pablo II, 1979: n. 14).

Para Laberthonnière, a diferencia del idealismo griego que conoce a Dios sub specie aeternitatis, el cristiano conoce a Dios sub specie temporis, cívicamente, en una cooperación-partnership. Esto no disminuye en nada su eternidad, pues su eternidad no es una especie de reloj roto, detenido, no es un "tiempo detenido donde no habría ya vida (...) pues Él es el máximo de la vida" (Laberthonnière, 1904: 74) y la eternidad no está fuera del tiempo sino en el tiempo.

Esto significa que no fuimos arrancados del pecado y del error por medio de una dialéctica que construye un mundo inteligible donde refugiarnos temporáneamente en un éxtasis catatónico, sino por la obra cívica de Cristo y por la fe en él (Laberthonnière, 1904: 98).

\section{La contemporaneidad de Cristo y los métodos histórico críticos}

A Laberthonnière interesa sobre todo la contemporaneidad cívica del hombre con Cristo que es Dios que se hace imputable por su pensamiento y actos en la historia. Surge entonces la pregunta de cómo vivir en el presente la pretensión de Cristo de ser juzgado por sus actos-obras, uno de los grandes temas del evangelio de Juan. De hecho, si Dios no fuera persona (pensamiento y voluntad), para los hombres no quedaría sino la imposible relación con una necesidad, con un Destino como para el idealismo griego.

Aquí se injertan las reflexiones de Laberthonnière (1904: 90) sobre la Iglesia que "vive por la presencia real y viviente de Cristo en ella". Significativas, ortodoxas y anticipadoras del Vaticano II son las afirmaciones de Laberthonnière sobre la Iglesia contendidas en esta obra ${ }^{29}$. Al mismo

29 Tresmontant (1966: 11) ha reconocido de modo muy genérico el aporte anticipatorio de Laberthonnière a la eclesiología del Concilio Vaticano II. De modo más preciso, Boisset (Laberthonnière, 1977: 306-307) ha mostrado los aportes de Laberthonnière a este Concilio, sobre todo en relación al conocimiento de la revelación entendida no como un listado de verdades, sino como presencia de una Persona, de Cristo. Además, Boisset muestra estos aportes en ámbito eclesiológico (Laberthonnière, 1977: 310-311), que derriban una "concepción piramidal de la Iglesia y un cesarismo 
tiempo que afirma decididamente que "adherimos a Cristo por él mismo" (Laberthonnière, 1904: 148), es decir, que la Iglesia no sustituye a Cristo, para él la Iglesia es "cuerpo místico" de Cristo, "comunión" (Laberthonnière, 1904: 90. 167) que no se puede separar de Cristo, pues de otra forma no se entendería su ministerio sacramental y su autoridad directora (Laberthonnière, 1904: 167-168). Laberthonnière (1904: 138) habla de "la Iglesia por la cual Cristo viene a nosotros y nosotros vamos hacia él, por la cual ligamos nuestra vida a su vida" y dice que "no se recibe ni se acoge la verdad de Cristo más que por el testimonio viviente de la Iglesia" (Laberthonnière, 1904: 148). Iglesia que "hace una sola cosa con Cristo siempre viviente" (Laberthonnière, 1904: 151). Por eso, "en la Iglesia y por la Iglesia, Cristo es por nosotros medio de salvación" (Laberthonnière, 1904: 163) y "a través de la realidad de la Iglesia, es la realidad de Cristo que es continuada y que se continua en la tierra" (Laberthonnière, 1904: 167).

Dicho esto, Laberthonnière puede así contraponer la Iglesia en que Cristo continúa vivo, presente, a la "Iglesia de la ciencia" con sus métodos historiográficos, a la iglesia que él llama "científica" fuera de la cual, y lo afirma con tono irónico "no habría salvación" (Laberthonnière, 1904: 142), a la iglesia clerical compuesta por los eruditos historiadores positivistas que tendrían en las manos -ellos solos- los instrumentos para conocer a Cristo (Laberthonnière, 1904: 152). Pretensión bien estúpida necia, dice Laberthonnière, pues la humanidad para creer en Cristo no ha esperado el desarrollo de los métodos históricos y filológicos que pretenden demostrar la existencia de Cristo y autentificar los textos (Laberthonnière, 1904: 152). Sin embargo, hay que notar que él no condena en absoluto un sano espíritu crítico, no tiene miedo de éste: "Bien lejos de que el Evangelio y la Iglesia se disuelven al fuego de la crítica, como por una parte se pretende hacer y por otra parte se tiene miedo (...) ella puede, al contrario, poner en luz su verdadero carácter y vitalidad" (Oratoriana, 1972: 183).

La Tradición eclesial, lejos de ser pensada como algo estático que se transmite en los siglos como "letra muerta", es una "vida" (Laberthonnière, 1904: 77. 172-173), es el acto mismo de Dios y, por eso, debe ser vivida orgánicamente trabajando con este pensamiento y acto de Dios que se ha revelado en Cristo $^{30}$. Es como si Laberthonnière dijera que toda Tradición debe ser recibida por el cristiano con beneficio de inven-

(césarisme) espiritual", fruto de una concepción de la revelación entendida como algo que cae de lo alto al modo del idealismo griego.

30 Ver las páginas que dedica a la Tradición viva de la Iglesia (Laberthonnière, 1904: 75-82).

VERITAS, No 35 (Septiembre 2016) 
tario, no de modo mecánico, sino viviente, por un conocimiento subjetivo y personal que permite "reconocer a Dios en el movimiento mismo de su vida" (Laberthonnière, 1904: 115), pues la verdad de Cristo es una "verdad orgánica y la fe es un crecimiento en el conocimiento de Dios, lejos de cualquier dogmatismo abstracto y rígido" (Laberthonnière, 1904: 115) constituido por una verdad ya hecha, típico del idealismo griego que pretende responder con ideas artificiales a los problemas reales del hombre. En fin, para Laberthonnière se necesita un dogmatismo viviente y flexible, pues la fe es igual a la relación con "un amigo que se conoce cada día más" (Laberthonnière, 1904: 96).

Contrariamente a lo que escribe Böhm (1997: 350) para el cual Laberthonnière "reduce todo a la acción, ya que su preocupación es la vida concreta de la acción", él está lejos de disminuir la importancia del pensamiento en la dinámica de la fe que es más bien un "realismo dinámico" (Laberthonnière, 1904: 101-102). Varias son las afirmaciones a este respecto: "Con la ayuda de la revelación, de la tradición, de la autoridad es necesario pensar personalmente" (Laberthonnière, 1904: 109-110); "Para vivir humana y religiosamente bay que pensar. (...) En lo ya hecho se debe buscar lo que se debe hacer, y en lo ya pensado lo que se debe pensar: es una lógica viviente" (Laberthonnière, 1904: 93), pues "hay que proporcionar un punto de aplicación a la invisible eficacia de la acción redentora" (Laberthonnière, 1904: 110). De este modo, las definiciones dogmáticas, lejos de pretender agotar el contenido y el objeto de la fe en conceptos ya hechos, son "direcciones que ellas dan y no cadenas que ellas imponen" (Laberthonnière, 1904: 94), pues la fe cristiana consiste en "la afirmación de un ser en quien se confía" (Laberthonnière, 1904: 95).

A este propósito, Laberthonnière, en el capítulo sexto (Laberthonnière, 1904: 117-153), muestra la insuficiencia del método históricocrítico tal como había sido desarrollado por el protestantismo liberal de los siglos XVIII y XIX. Para él, "saber que Cristo ha existido no significa creer en él" (Laberthonnière, 1904: 120). Agudamente ataca el método histórico-crítico de esta teología, ya que pretende encontrar el origen de la fe en una reconstrucción histórica exhaustiva de la figura de Cristo, es decir, estudiando a Cristo como se estudia a Alejandro Magno o a Julio Cesar, como un hecho del pasado (Laberthonnière, 1904: 119.124). De esta forma, este supuesto método histórico-crítico no sólo termina en contradicciones entre sí (Laberthonnière, 1904: 133), sino que elimina a Cristo antes de estudiarlo, pues lo echa y recluye en un pasado lejano. Dos años más tarde, en 1906, Schweitzer (1990), en su famoso Historia de la investigación sobre la vida de Jesús, había llegado a la misma conclusión, de que era imposible reconstruir históricamente la figura de Cristo. 
Al contrario, la pretensión de Cristo es justamente la de no ser un hecho del pasado que se alcanza a través de una erudición supuestamente neutral, sino una realidad presente: "En la enseñanza de la Iglesia, Cristo no se ofrece como un hecho del pasado (...) sino como una realidad presente" (Laberthonnière, 1904: 122-123). Presencia que hace vivir al hombre, pues es conveniente, correspondiente a su deseo: "Es viviendo y no simplemente haciendo historia o crítica que se acoge la verdad de Cristo" (Laberthonnière, 1904: 157). A este respecto, Laberthonnière (1977: 93) se opuso a Lebreton para el cual "el dogma no corresponde a nada de lo que nosotros somos y de lo que experimentamos" como si fuera un "bloque caído del cielo" (1977: 83). La apologética de Laberthonnière quiere mostrar, al contrario, la conveniencia y correspondencia de la revelación de Cristo a lo que es el hombre, a sus urgencias existenciales. En este sentido, se opuso a una concepción deductivista, extrinsecista, lógica, mecánica de la revelación que viene desde afuera, desde arriba, sin ninguna relación con el hombre, como un bloque de nociones que el hombre debería sólo acatar sin poder entender su razonabilidad existencial, como "un bloque nocional de verdades que se imponen al nosotros sin poder ser la verdad de nosotros" (Laberthonnière, 1977: 174).

Esto no significa que, para Laberthonnière, no sea necesaria la investigación histórica en la fe cristiana (1904: 155-190). Por eso, elogia a Bossuet, creyente e historiador, que ha sabido encontrar en el cristianismo la verdad vital que Cristo es para nosotros (Laberthonnière, 1904: 131). En efecto, menospreciar la historia significaría desconocer el realismo cristiano y no reconocer que Dios en Cristo se hizo y se hace presente, imputable en la historia. Significaría no reconocer que el Evangelio es el testimonio histórico de los apóstoles acerca de la verdad de Cristo, verdad que es una sola cosa con su realidad histórica (Laberthonnière, 1904: 159. 165).

Así, por un lado, el acontecimiento cristiano es mucho más que una historia que se puede poner en fichas y archivarla, es un acontecimiento que huye de una mirada meramente historiográfica-positivista que quiere reducir lo viviente a lo abstracto, a lo ya sabido por una camarilla de eruditos que representarían "una especie de academia de mandarinos" (Laberthonnière, 1904: 132) que repiten una vez más los contenidos abstractos del idealismo griego. Para Laberthonnière, como escribe en una carta de 1904, entre estos "mandarinos" historicistas están "el padre Lagrange y Mons. Batiffol que tienen realmente la pretensión de que les basta la exégesis y la teología positiva" (Poulat, 1974: 500). Juicio que nos parece injusto. 
Por otro lado, hay "una historia propiamente dicha de Cristo y de sus discípulos" (Laberthonnière, 1904: 160) de la cual se puede reconocer su carácter histórico. Por eso, la fe puede utilizar la "historia" con provecho, ya sea para reconocer la realidad histórica de Cristo en su existencia terrenal, ya sea para que "su verdad sea considerada en los testimonios que la han expresado" (Laberthonnière, 1904: 162). Cristo tiene en los hombres que él encuentra "una acción interior y exterior" (Laberthonnière, 1904: 163) y el único método adecuado para conocer a Cristo como hecho histórico, como verdad para el hombre y no como mito o fábula puede sólo ser éste: "Es aprendiendo a creer en él, a causa de lo que él es [en el presente] que nosotros aprendemos y creemos lo que él ha sido [en el pasado] (Laberthonnière, 1904: 164).

A este propósito, el protestantismo se ha equivocado porque ha pensado el contenido de la fe cristiana testimoniado en la Escritura como algo "inmóvil", como un bloc de granit, un "bloque de granito" (Laberthonnière, 1904: 178), terminando en una creencia supersticiosa en los textos de la Biblia considerados como "oráculos que cada uno no tiene más que consultar para recibir la respuesta que esperaba" (Laberthonnière, 1904: 178-179). El éxito de esta concepción es que el acontecimiento cristiano se ha disuelto en una "nebulosa evanescente (...) pues como acontece a un cuerpo del que se retira el alma, así el contenido del cristianismo se ha disuelto para ellos" (Laberthonnière, 1904: 179). Y se ha disuelto justamente porque se ha hecho de este contenido "una especie de absoluto caído del cielo, una cosa completa y acabada, lo divino sin lo humano" (Laberthonnière, 1904: 180), un sobrenatural que no tiene relación viva con el hombre. De este modo, para Laberthonnière, el protestantismo no es sino una consecuencia del idealismo griego.

Sin embargo, del mismo modo que el protestantismo, los "tradicionalistas" con su dogmatismo rígido "no quieren descender en el terreno de la historia y de la crítica" (Laberthonnière, 1904: 181), pues piensan que el contenido de la fe cristiana es un "bloque" de piedra y "no un organismo que se comporta como un organismo" (Laberthonnière, 1904: 183). Ambos, protestantismo y tradicionalismo, sólo saben hacer síntesis rígidas, mientras "la síntesis real se muestra flexible (souple) y es por la flexibilidad y no por la rigidez que la fe es resistente y conquistadora" (Laberthonnière, 1904: 184).

\section{El pensamiento de Cristo}

Para Laberthonnière, Cristo no ha pretendido ser un "teólogo" (Laberthonnière, 1904: 199), no ha venido para hacer un discurso o dictar un libro que se habría registrado de modo estenográfico (Laberthonnière, 
1904: 185). Cristo no ha pretendido comunicar una verdad que debe ser recibida por los hombres "ya hecha y ya formulada" (Laberthonnière, 1904: 187).

El acontecimiento de Cristo es histórico, lo que implica que es también una doctrina, es decir, un pensamiento: es una "doctrina concreta" (Laberthonnière, 1904: 39) que nos da cuenta "de las condiciones de nuestra existencia, de lo que somos y de lo que debemos hacer" (Laberthonnière, 1904: 40).

Es un pensamiento original que contiene una metafísica ${ }^{31}$. Para Laberthonnière, la metafísica del Evangelio y del Nuevo Testamento es "una interpretación directa de Cristo mismo captada en su realidad y en sus manifestaciones temporales, para descubrir por él la presencia y la acción en nosotros de un Dios Padre" (Laberthonnière, 1904: 56). En una carta escribe: "Para mí, Cristo es el eje (pivot) de una metafísica que no se superpone (superpose), sino que sustituye a todo lo que se ha llamado filosofía" (Hendecourt, 1947: 12). Es evidente que esta "filosofía" es la platónico-aristotélica que ha continuado dominando en la historia del pensamiento. De hecho, para los apóstoles y evangelistas, Cristo "no era un simple hecho histórico que ellos constataban y reporteaban, sino el principio y el alimento de una fe por la cual han vivido y han muerto" (Laberthonnière, 1904: 58). De este modo, "no se puede establecer científicamente su testimonio" (Laberthonnière, 1904: 58) y Cristo no puede ser reducido a objeto de mera certeza histórica, pues es "una realidad que se vuelve objeto de fe, es decir, una realidad sobre la cual nos apoyamos para vivir. (...) Cristo no es solamente un hecho exterior a nosotros que se produce en el pasado. (...) Si nos adherimos a Cristo no es por simple constatación empírica, sino porque reconocemos que nuestro ser hunde sus raíces en él" (Laberthonnière, 1904: 60).

En el último capítulo de El realismo cristiano y el idealismo griego, Laberthonnière habla del "pensamiento de Cristo" en contra de aquellos que piensan que, siendo el dogma inmutable, también Cristo habría tenido como un dispositivo mecánico-ontológico-dogmático que lo deslegitimaría de pensar en la verdad de su persona y de su misión, en la verdad que Él era y es para los hombres, pues de esta verdad Él habría tenido sólo un "sentimiento vago y mal definido" (Laberthonnière, 1904: 196).

Si Cristo no fuera un pensador que pensaba con su razón en la verdad de su persona, que era definida en relación con el Padre y el Espíritu, si Cristo no fuera un pensador que viviendo y muriendo no conocía la

31 Desde su juventud, la inquietud de Laberthonnière fue la de "no separar de modo radical metafísica y religión” (Abauzit, 1936: 6). Sería más pertinente decir que Laberthonnière rechazaba la separación entre metafísica y pensamiento de Cristo.

VERITAS, No 35 (Septiembre 2016) 
verdad que él era y es para nosotros, él no habría sido nuestro "Mediador y Redentor", habría sido sólo una "victima inconsciente y, en consecuencia, estéril" (Laberthonnière, 1904: 196). Nótese esta observación de Laberthonnière: si Cristo no tuviera un pensamiento sano, si fuera patológicamente víctima inconsciente, sin un pensamiento propio, su redención sería estéril. Es la acusación moderna hecha al pensamiento de Cristo de ser psicopatológico ${ }^{32}$. Al contrario, para Laberthonnière sólo si Cristo tiene un pensamiento sano, es decir, imputable, puede salvar. Cristo salva al hombre porque es sano, pues nadie quiere ser salvado por un demente. Salud y salvación vienen así a coincidir para el hombre que, por Cristo, es sano y salvo. En efecto, "Cristo no ha sufrido un destino más fuerte que él” (Laberthonnière, 1904: 196) y, por eso, su agonía y pasión es "esencialmente un acto de amor" (Laberthonnière, 1904: 197). De este modo, su pasión es la acción suprema de Cristo que, habiéndose hecho solidario con la humanidad, ha hecho a la humanidad solidaria con él y la ha llevado de modo libre y voluntario a su Padre (1904: 198).

En este sentido, es equivocado decir que Laberthonnière "quiere pensar religiosamente, religiosear (religioser) su pensamiento" (Guerin, 1939: 29) como si Cristo pensara en Dios y no en el Padre y según su pensamiento. Esto significaría adscribirlo al modernismo, al religiosismo modernista. Al contrario, el pensamiento de Laberthonnière es, fiel al pensamiento de Cristo, pensamiento patrologico, pensamiento del Padre. En este sentido, tampoco es un pensamiento teo-lógico.

En este punto se injerta la reflexión de Laberthonnière sobre la relación Cristo-dogma. No siendo un "teólogo", Cristo "no ha querido hacer una teoría de sí mismo" (Laberthonnière, 1904: 199), no ha querido fijar para siempre su pensamiento en un lenguaje ya hecho, dogmáticamente concluido y frente al cual no quedaría nada por comprender o decir. Cristo no ha querido sustituirse a los hombres, pues de este modo su pensamiento, verdad y vida, serían una teoría sobrenatural griega y Él

32 Albert Schweitzer (2001) en 1913 escribió una obra muy poco conocida Diagnosis y valoración psiquiátrica de Jesús (el titulo original de la obra de Schweitzer es Die psychiatrische beurteilung Jesu). En el prefacio dice que quiere retomar la hipótesis introducida por Strauss que "designa la figura de Jesús en los términos clásicos de la psicopatología”. En el meollo de su obra trata de las distintas opiniones siquiátricas de varios autores de inicio del siglo XX (De Loosten, Hirsch, Binet-Sanglé, Rasmussen) sobre la salud mental de Cristo, opiniones que afirmaban de una u otra forma que Jesús era paranoico, esquizofrénico, megalómano, masoquista, sádico, parafílico, melancólicodeprimido, neurótico obsesivo, histérico, fanático, bueno y santurrón. La conclusión de Schweitzer es un no liquet ("aún no está claro"), una solución "pilática”, como subraya en su introducción G.B. Contri. Notamos que este pensamiento relatado por Schweitzer no es nada más que un "docetismo ilustrado", pues es el rechazo del "cuerpo", es decir, del pensamiento sano de Cristo. 
terminaría siendo "extraño y exterior" al hombre (Laberthonnière, 1904: 200). Para Laberthonnière, si Cristo se ha acomodado a los hombres, si ha hablado el lenguaje de los hombres que ellos podían entender, no lo ha hecho para fingir, pues de este modo su humanidad sería una mera apariencia. Esto sería el docetismo que se imagina a Cristo como un matemático o un filósofo que habla a gente ignorante con su lenguaje especializado (Laberthonnière, 1904: 201). Al contrario, Cristo se ha hecho realmente hombre, se ha realmente introducido en su ambiente para vivir y actuar en él: esto es el "milagro de la caridad" de Cristo (Laberthonnière, 1904: 201-202).

A este propósito, Laberthonnière comenta espléndidamente el himno cristológico de la Carta a los Filipenses: "Permaneciendo en lo que era en sí mismo, se ha mezclado con los hombres, ha compartido realmente su suerte, ha trabajado con ellos, ha sufrido con ellos, ha tenido hambre y sed. (...) La caridad ha hecho en él, en Cristo, la síntesis de lo divino y de lo humano, excepto en el pecado" (Laberthonnière, 1904: 203). Bien lejos del dios del idealismo griego que no necesita trabajar puesto que "ya es y nada más", el Dios cristiano trabaja con los hombres. Su naturaleza es el trabajo, no la aristotélica contemplación de sí mismo.

Para Laberthonnière no se puede pensar en Cristo y en la misma Iglesia, que es Cristo que continua en la historia, con las categorías del idealismo griego. No se puede "transformar en especulación abstracta la solución de un problema vital" (Laberthonnière, 1904: 203). Este "problema vital" es como el fil rouge, el contenido específico de esta obra de Laberthonnière que pone en guardia a los cristianos para que no reduzcan la respuesta que es la persona de Cristo, su pensamiento y obras, respuesta al problema vital de la existencia humana, a una explicación dogmática concluida, ya hecha, presupuesta y dada por descontada.

Esta especulación abstracta repetiría la del idealismo griego y serviría sólo para tranquilizar y anestesiar clericalmente a los cristianos, sin urgirlos a la necesidad de un trabajo de partnership, de sociedad con Cristo. En efecto, "Cristo ha venido justamente para fundar una vida y, por eso, una sociedad" (Laberthonnière, 1904: 185). Para Laberthonnière, "cuando el hombre le dice 'sí', formamos con Dios una sociedad, una unión, en lugar de absorbernos en Él como si nosotros fuésemos una esencia que vuelve a una Esencia" (Oratoriana 1972: 192). Abauzit (1934: 21) sintetiza de este modo este pensamiento de Laberthonnière: "No se trata de una absorción que suprimiría nuestra personalidad, se trata de una comunión". Sociedad no de esclavos sumisos a una especulación "sobrenatural" y ajena a la existencia humana, sino una unión, una comunión de socios, amigos del pensamiento de Cristo para los cuales es realidad la 
frase de san Pablo citada por Laberthonnière: Mibi vivere Christus est ${ }^{33}$. Infinita es aquí la distancia con el idealismo griego para el cual sólo los esclavos trabajan en la polis, siendo así meros instrumentos, cosas (Laberthonnière, 1904: 195) ${ }^{34}$. El pensamiento de Cristo afirma, al contrario, que "mi Padre trabaja siempre y yo también" (Jn 5, 17). Este trabajo es propiamente el trabajo no sólo al interior de la Trinidad, sino el de partnership con el hombre. De este modo, "entre Dios y el hombre no existe ni la trascendencia que pone el primero fuera del alcance del segundo, ni la separación" (Guerin, 1939: 15-16) ${ }^{35}$.

Para Laberthonnière, en los tiempos modernos en que muchos crucifican a Cristo, hay otros, los cristianos, que están preocupados únicamente de poner a Cristo "en una tumba con sus fajas rígidas" (Laberthonnière, 1904: 214), las fajas de los dogmas idealistas de influencia griega que permitirían mirar las peripecias de una batalla desde afuera y desde lo alto, sin tomar parte en ella para no arriesgar una tranquila seguridad dogmática.

\section{Conclusión}

Laberthonnière, de algún modo, retoma la cuestión puesta por Tertuliano (2001: 165-169) a los cristianos de su tiempo ${ }^{36}$ : "Desdichado Aristóteles, que les ha enseñado la dialéctica, maestra en el arte de construir y destruir, astuta en las proposiciones, forzada en las conjeturas, firme en las argumentaciones, obradora de disputas. (...) ¿Qué tiene, por

33 Guerin (1939: 5) ha señalado, de modo interesante, que "el punto de partida de Laberthonnière es la experiencia que él ha hecho del ejercicio de la autoridad". Sería mejor decir de una "autoridad" eclesial tal como era mal concebida en aquel tiempo entre los cristianos, lo que implicaba la subordinación y sometimiento a algo exterior, a una autoridad de comando que eliminaba cualquier autoridad de competencia individual que pretendía tener alcance universal. En este sentido, en aquellos tiempos Batiffol inscribía a Laberthonnière en el subjetivismo kantiano (Poulat 1974: 334). Guerin continúa diciendo (1939: 6) que Laberthonnière de este modo ha hecho "surgir una metafísica de una concepción práctica".

34 Con respecto a este tema ver Guerin (1939: 7).

35 Guerin (1939:16) continúa diciendo de modo "poético" que entre Dios y el hombre hay "un camino (route) abierto sobre el cual uno y el otro pueden ir uno hacia el otro". Para Guerin (1939: 28), "el Dios de Aristóteles es talmente trascendente que ninguna acción puede venir de él hacia el mundo". Cursiva nuestra.

36 Jaeger (1998: 52) escribe que Tertuliano, proponiendo por la primera vez el problema de la fe y de la razón, "se enfrenta a la tendencia de los pensadores de su época, tanto griegos como cristianos, que pretenden entender el cristianismo como una nueva filosofía comparable a la filosofía griega del pasado" (Jaeger, 1998: 53). Puestos así los términos, Laberthonnière parece no retomar la lección de Tertuliano. Nosotros pensamos lo contrario. 
tanto, en común Atenas y Jerusalén (Quid ergo Athenis et Hierosolymis)? ¿Qué tienen en común la Academia y la Iglesia? ¿Qué tienen en común los herejes y los cristianos? Nuestra doctrina viene del pórtico de Salomón que, también él, había enseñado que el Señor ha de ser buscado con simplicidad de corazón. Allá se las vean los que han inventado un cristianismo estoico, platónico, dialéctico". Tertuliano, en este famoso texto, pone en cuestión la validez de "pensar en griego" los contenidos del pensamiento hebreo de Cristo. Superficialmente se ha reprochado a Tertuliano el sostener la no razonabilidad de la fe. Nos parece que, al contrario, Tertuliano afirma la razonabilidad intrínseca del pensamiento hebreo de Cristo (engendrado en "Jerusalén") que no necesita de argumentos griegos para dar razones de la fe cristiana. Es decir, para Tertuliano la fe que proviene del pensamiento hebreo de Cristo es intrínsecamente razonable, tiene razones, sin necesidad de recurrir a la razón griega ${ }^{37}$.

Estas preguntas y cuestionamientos hechos por Tertuliano han sido proseguidos, de algún modo, por Laberthonnière en El realismo cristiano y el idealismo griego, preguntas y cuestionamientos que la teología actual podría valorar, pues pueden ser fecundas de un pensamiento teológico que resultaría nuevo justamente porque es al mismo tiempo fiel al de Cristo. La fe cristiana que vive del pensamiento hebreo de Cristo, ¿no es un pensamiento razonable en sí? ¿Es necesario recurrir, para mostrar la razonabilidad de la fe, al aporte de la razón que sería propiedad exclusiva del idealismo griego de Platón y, sobre todo, de Aristóteles? ¿La fe no tiene razón? ¿El pensamiento hebreo de Cristo es sólo una fe religiosa (en el Padre) que no posee intrínsecamente razones? ¿El cristicidio actuado en ámbito cristiano, no ha consistido y no consiste justamente en menospreciar el pensamiento hebreo de Cristo? Si el cristiano posee, como afirma san Pablo, el pensamiento de Cristo, este pensamiento es hebreo, no es ontológico griego, para el cual el árbol se conoce por el árbol, por su esencia oculta. En efecto, el pensamiento hebreo y de Cristo es jurídico-económico ${ }^{38}$ : el árbol se conoce-imputa (dimensión "jurídica”) por los frutos-beneficios-provechos (dimensión económica). Entonces, ¿de dónde la necesidad de recurrir para la inteligencia de la fe a las categorías estático-ontológicas del pensamiento idealista griego?

La originalidad de Laberthonnière consiste en haber entendido la oposición del pensamiento filosófico griego con el pensamiento cristiano

37 Esta lección de Tertuliano no ha sido retomada en el ámbito teológico ni filosófico cristiano $\mathrm{y}$ ha sido removida. Para una reseña de esta oposición que, inspirándose en 2 Co 6, 14-16, está casi ausente en la Patrística (Tertuliano, 2001: 167).

38 En el ámbito limitado de este artículo, no podemos dar cuenta de esta afirmación, que requeriría un estudio más amplio.

VERITAS, No 35 (Septiembre 2016) 
y de haber mostrado además las consecuencias para la fe de esta asunción acrítica-fideista, diríamos docetista ${ }^{39}$. Habría tenido que subrayar más que este pensamiento cristiano, que es el pensamiento de Cristo, es justamente antitético al pensamiento ontológico-esencialista griego en cuanto es pensamiento hebreo (bíblico), es decir, "jurídico-económico", pensamiento de una oeconomia salutis universal, engendrada por el pensamiento de Cristo y del Padre imputable por sus "frutos", por sus "actos".

A este propósito, retomar el pensamiento hebreo de Cristo como principio hermenéutico definitivo significaría para la teología actual evitar cualquier marcionismo, cualquier separación entre Antiguo y Nuevo Testamento que puede estar siempre latente. Significaría, por ejemplo, reconocer (aunque parezca un dato obvio) que el Dios de Jesucristo no es un genérico Dios religioso-ontológico, sino es el Dios de la Alianza con Israel, un Dios bíblico, un Dios que es Dios porque es Padre, no en cuanto dotado a priori de atributos ontológicos. Además, nutrirse del pensamiento hebreo de Cristo implicaría para la teología actual constituirse como una teología hebreo-católica ${ }^{40}$. Más radicalmente, la teología actual podría volver a re-pensar sus contenidos con un pensamiento "jurídico-económico" que es el de Cristo, el de la imputación de los frutos, no de esencias ontológicas que son inimputables. Esto no lleva de ningún modo a rechazar la ontología de los contenidos teológicos, sino más bien a encontrar esta ontología en un pensamiento "jurídicoeconómico", el de la oeconomia salutis Trinitaria. Oeconomia que es la misma de Cristo que, en cuanto heredero, revela este pensamiento patrimonial a los cristianos, según la definitiva expresión de san Pablo: "Y si hijos, también herederos, herederos de Dios, y coherederos de Cristo" (Ro 8, 17). El pensamiento teológico y de la fe de todo cristiano sería así un pensamiento de hijos-herederos y no sucumbiría bajo una epi-steme griega entendida como un conocimiento que se impone desde lo alto. De este modo, las enormes y, a nuestro parecer, insuperables dificultades que implica para la teología y la fe cristiana una asunción acrítica del pensamiento ontológico-ontologista griego (entre otras: la relación Eternidad-tiempo, Infinito-finito, Sobrenatural-natural, Gracia-libertad) encontrarían en la retoma del pensamiento hebreo-jurídico-económico de Cris-

39 En el siglo XX, esta lección ha sido retomada de modo parcial por Tresmontant (1955 y 1962) con resultados que podrían haber sido mucho más precisos y decisivos.

40 Von Balthasar (1986) ha hablado del "eterno destino de Israel oscurecido de platonismo". Laberthonnière agregaría también el aristotelismo. Para la constitución de una teología con arraigo en el pensamiento hebreo y de Cristo, sería interesante tomar en cuenta los datos contenidos en la obra de Danielou sobre la teología judío-cristiana que tenía el mérito de ser una “teología de la historia” (Danielou, 1958: 434). 
to una solución mucho más simple, católica, es decir, adecuada al pensamiento laicamente sano de cualquier hombre.

Volver a leer de manera cordial la lección contenida en El realismo cristiano y el idealismo griego puede hacer entrever atisbos de esta originalidad del pensamiento hebreo de Cristo que, sin despreciar el idealismo griego es, sin embargo, otra raza de pensamiento. De hecho, Laberthonnière escribe que los Evangelios son un testimonio de la fe que no ha sido formulado en abstracto, sino en una sociedad, la hebrea, que "este testimonio ha nacido de ésta y en ésta" (Oratoriana, 1972: 183-184). Sintetizando el pensamiento de Laberthonnière, Abauzit (1934: 17) ha afirmado: "El Dios del Evangelio no es el Dios de Platón o de Aristóteles". Laberthonnière habría bien podido poner como lema de esta obra la frase de Cristo: Unaquaeque enim arbor de fructu suo cognoscitur, "cada árbol se conoce por los frutos". Unaquaeque: cada raza de pensamiento tiene sus frutos que son propios, originales. Por sus frutos-beneficios-provechosganancias producidas en la historia se puede conocer, es decir, imputar, juzgar cada pensamiento. Laberthonnière, en El realismo cristiano y el idealismo griego, muestra que los frutos del pensamiento de Cristo son sanos, reales (el "realismo cristiano"), buenos, humanamente razonables, convenientes para el hombre. El reverso de esta cuestión constituye la necesidad de preguntarse si los frutos del idealismo griego son igualmente sanos y buenos para la producción de una oeconomia salutis que sea conveniente para el hombre $e^{41}$.

Frente al Dios inimputable del idealismo griego, que se hace fuerte por sus atributos ontológicos presupuestos y que no necesita validar en la historia, el Dios cristiano se propone en Cristo como imputable en la historia, mostrando la validez de sus atributos ontológicos en los frutos de la construcción de la civitas Dei que es engendrada en cooperación con los hombres, socios de trabajo, no esclavos sumisos de un idealismo griego (e islámico) falsamente sobrenatural.

\section{REFERENCIAS}

-Abauzit, F. (1934). La pensée du Père Laberthonnière. Revue de théologie et philosophie (90), 5-33.

-Balthasar von H.U. (1981). El complejo antirromano: integración del papado en la Iglesia universal. Madrid: Biblioteca de Autores Cristianos.

-Balthasar von H.U. (1986). Gloria. Estilos laicales. Madrid: Encuentro.

41 Böhm (1997: 350) escribe justamente que la intención de Le réalisme chrétien es "hacer inteligible que algunas filosofías - medidas por su valor para la vida- dan más sentido que otras".

VERITAS, No 35 (Septiembre 2016) 
-Böhm, I. (1994). Modernismo y antimodernismo. En E. Coreth, W. Neidl \& G. Pfligersdorfer (Ed.), Filosofía cristiana en el pensamiento de los siglos XIX y XX (Tomo II, pp. 301-315). Madrid: Encuentro.

-Böhm, I. (1997). Lucien Laberthonnière. En E. Coreth, W. Neidl \& G. Pfligersdorfer (Ed.), Filosofía cristiana en el pensamiento de los siglos XIX y XX (Tomo III, pp. 344-353). Madrid: Encuentro.

-Castelli, F. (1931). Laberthonnière. Paris: Vrin.

-Dei verbum (2000). Concilio Vaticano II. Madrid: BAC.

-Danielou, J. (1958). Théologie du judéo-chistianisme. Paris: Desclée.

-Gilson, E. (1962). El filósofo y la teología. Madrid: Guadarrama.

-Guerin, P. (1939). L'idée de Dieu d'après Laberthonnière. Revue de théologie et de philosophie (27), 5-32.

-Hendecourt, M. (1947). Essai sur la philosophie du Père Laberthonnière. Paris: Vrin.

-Jaeger, W. (1998). Cristianismo primitivo y paideia griega. México D.F.: Fondo de cultura económica.

-Juan Pablo II (1979). Redemptor hominis. Santiago: San Pablo.

-Laberthonnière, L. (1904). Le réalisme chrétien et l'idéalisme grec. Paris: Lethellieux.

-Laberthonnière, L. (1966). Le réalisme chrétien précedé de Essais de philosophie religieuse. Paris: Seuil.

-Laberthonnière, L. (1977). Dogme et théologie. Paris-Gembloux: Duculot.

-Martina, G. (1978). La Chiesa nell'età dell'assolutismo, del liberalismo, del totalitarismo. (Vol. IV). Brescia: Morcelliana.

-Molteni, A. (2015). El docetismo gnóstico y el pensamiento-cuerpo real de Cristo. En D. Mundaca (Ed.), Un espacio a las aventuras del cuerpo. Estudios interdisciplinarios sobre la historicidad del cuerpo (pp. 77-96). Concepción: Universidad de Concepción.

-Mushete, N. (1978). Le probleme de la connaissance religieuse d'après Lucien Laberthonnière. Kinshasa: Faculté de Théologie Catholique.

-Olgiati F. (1933). La filosofia religiosa di Luciano Laberthonnière. Rivista di filosofia neo-escolastica (1), 11-49.

-Oratoriana (1972). Laberthonnière. L'homme et l'oeuvre. Introduction a sa pensée. Paris: Beauchesne.

-Péguy, C. (1992). CEuvres en prose completes, Vol. III. Paris: Gallimard.

-Perrin, M. (1975). Laberthonnière et ses amis. Birot, Bremond, Canet, Le Roy. Paris: Beauchesne.

-Perrin, M. (1980). La jeunesse de Laberthonnière. Paris: Beauchesne.

-Perrin, M. (1983). Dossier Laberthonnière: correspondance et texte (1917-1932). Paris: Beauchesne.

-Provencher, N. (1992). Modernismo. En (Ed.), Diccionario de teología fundamental (pp. 1013-11017) Madrid: San Pablo.

-Poulat, E. (1974). La crisis modernista. Historia, dogma y critica. Madrid: Taurus.

-Schmidinger, H. (1994). Visión de conjunto de la neoescolástica en Francia y en Bélgica. En E. Coreth, W. Neidl \& G. Pfligersdorfer (Eds.), Filosofía cristiana en el pensamiento de los siglos XIX y XX (Tomo II, pp. 181-190). Madrid: Encuentro. 
-Schweitzer, A. (1990). Investigaciones sobre la vida de Jesús. Valencia: Edicep.

-Schweitzer, A. (2001). Diagnosi e valutazione psiquiatrica di Gesú. Recuperado de http://www.sicedizioni.it/

-Tertuliano (2001). Prescripciones contra las herejías. Madrid: Ciudad Nueva.

-Tresmontant, C. (1962). Ensayo sobre el pensamiento bebreo. Madrid: Taurus.

-Tresmontant, C. (1955). Estudios de metafísica bíblica. Madrid: Gredos.

-Vilanova, E. (1992). Historia de la teología cristiana. Barcelona: Herder.

Sumario: Introducción; 1. Un sobrenatural deshumano; 2. El Dios cristiano y la onto-teologia griega; 3. La ciudad cristiana de Dios y del hombre; 4. La contemporaneidad de Cristo y los métodos históricos críticos; 5. El pensamiento de Cristo; Conclusión; Referencias. 